\title{
Towards a Grey Ecology
}

\author{
Stefana Broadbent and Claire Lobet-Maris
}

\section{Economy of Attention: From Abundance to Scarcity}

We often refer to the digital society as a society of abundance inasmuch as informational resources are concerned, in contrast to previous ages in which information was scarce, difficult to access and to disseminate. However, from the human perspective, this evolution may have transformed what was abundant in the past - the capacity to attend to information - into a much more scarce and widely distributed asset. If we follow the prevailing cognitivist model of attention, which postulates a mental architecture that has extensive computational power but significant intrinsic limitations in the capacity to attend to information, the formidable multiplication of informational content is inevitably determining a competitive view of the allocation of this mental resource. Following the social and economic logic of all scarce resources, we are therefore witnessing the creation of a market for attention.

According to KESSOUS and alii (2010), the term 'economy of attention' was coined by M. H. Goldhaber (1997) as a more appropriate way to discuss the economic models of the information society than the traditional industrial and monetary approaches. But the concept was not new. In the early 70's, Herbert Simon had already suggested that

... in an information-rich world, the wealth of information means a dearth of something else: a scarcity of whatever it is that information consumes. What information consumes is rather obvious: it consumes the attention of its recipients. Hence a wealth of information creates a poverty of attention and a need to allocate that attention efficiently among the overabundance of information sources that might consume it... (Simon 1971, pp. 40-41).

The main tenant of this economic model is that, in an ecosystem in which attention is scarce and information abundant, being able to attract user focus has a huge

\footnotetext{
S. Broadbent $(\bowtie)$

University College London, UK

e-mail: stefana.broadbent@ucl.ac.uk

C. Lobet-Maris

University of Namur-Belgium, Namur, Belgium

e-mail: claire.lobet@unamur.be 
value. Value is therefore created not by the information itself, but by creating an environment capable of drawing the attention of the greatest number of people for the longest amount of time.

This strategy underlies the business model of the majority of successful internet businesses. The crucial differentiator is not the production and distribution of content but the filtering, contextualization and organization of information. It is the structuring of content and the ability to make information more visible, and so more likely to be attended to, which supports the development of environments that are capable of drawing attention. When this is accompanied by techniques to measure, quantify and monetize attention, new mechanisms of trading can be developed. Although this has been the business case of the media for the last century, interactive media allows a far greater level of granularity and precision in the measurement of audience focus. The quantity and complexity of data produced by interactive systems, accompanied by self-learning capabilities, also allows for a completely new scale of analysis - as it is obvious from the debates around big data. We have therefore a simultaneous movement towards an increasingly granular and individual identification of attentional patterns and the accumulation of massive aggregated sets of user behaviours. Together, they engender an exceptionally valuable commodity for whoever has access to it. There is therefore a definite and unquestionable business drive to create digital environments capable of attracting audiences and keeping them there as long as possible.

Alongside the new economies being built more or less explicitly on the monetization of attentional processes, there is a growing concern regarding the subjective perception of loss or distortion of attention. Some well known authors like N. Carr (2011), S. Turkle (2011), J. Laniar (2011), have articulated the emerging discomfort felt by many of those regularly immersed in digital activities that they are losing their capacity to focus. The feeling of losing agency when engrossed in digital endeavours, and a dwindling sense of control on attention, is reported by many users (Zeldes et al. 2007; Misra and Stokols 2012; Marulanda and Jackson 2012). Once again, most explanations of this phenomenon invoke the limits of human ability to cope with an overabundance of information and devices. This malaise is too widespread to be waved away as a dystopian argument of ageing intellectuals clinging to old-fashioned models of learning and working. In our opinion, there is a true battle being waged around attention, with increasing economic, political and social stakes, and it is worth analysing some of its conceptual foundations.

We believe that the first step is to go beyond a purely cognitive perspective, which in our view forgets the centuries of social techniques to control and manage attention, and corners the issue into an excessively individualistic framework. We strive to put this issue into not only a socio-historical but also a political framework. It is our belief that the issue cannot be reduced to one of abundance vs. scarcity, and that the reported subjective sense of loss of focus and control that many users of digital media experience may be due not to the simple fact of being exposed to too much information on too many screens, but to the transformation and deprivation of the social environments that support the attribution of meaning. 
Looking back, we have always lived in excessively stimulating environments, both in social and in physical terms, and attentional processes have allowed us to operate successfully in such spaces. Our material and physical environments are as rich and as complex as our digital ones, probably even more so. We have been successful in the physical space because, among other reasons, artefacts and social norms have sustained the cognitive processes of attention by orienting and significantly reducing the attentional demand of our physical environments. Traditionally, we have built spaces that orient our attention toward a certain direction-pulpits, tribunes, platforms and stages indicate to whom we should listen to and attend; museums and galleries signify what is worth looking at. We have ordered, classified and organized artefacts to signal their rank. In the social sphere, we have elaborated culturally shared signs that guide attention, indicators of social status that provide clues about whom we should attend to with priority. In other words, alongside the physiological responses that guide our attention in an automatic way (e.g. when there are sudden menacing noises or rapid movements), we have socially and collectively generated environments that orient and support our focus. If we adopt a model of cognition that distributes (Hutchins 1995) the burden of processing among artefacts, people and organizations, attention can be seen as a process supported by socially constructed environments.

We would like to argue that the new economic models, which increasingly attempt to exert control on what is attended to, together with the opaqueness and fragmentation of digital environments, have a joint detrimental effect on users' sense of focus and agency. Because of their nature and their novelty, digital systems are stripped of the traditional signs of intelligibility and relevance, which generally help us navigate the material world. This means that, in many cases, we have lost our cognitive and social props, and therefore the competition for attention has become much more primitive and brutal, and much more reliant on very basic attentional techniques (such as limiting the alternatives). This brutality is reinforced by what Z. Bauman $(2005,2007)$ and R. Sennett (2005) describe as the difficult conditions of the modern social existence, which put a higher burden on the individual as a consequence of the weakening of our traditional institutions of socialization.

\section{Disembodiment and Data-ification of Experiences}

There are many ways in which digital environments seem to have stripped material environments of their "readability", thus pushing onto the individual the effort to decide what should be attended: the excessive complexity of the computational systems that create hierarchies and classifications that are opaque in their constitution (as is obvious in big data); the increasing standardization and fragmentation of activities to comply with a coding logic; the expansion of the networks of actors and the detachment of their traces from any specific identity. These are all different facets of a similar phenomenon that we could call disembodiment or data-ification of experiences. 
Algorithmic systems, acting as new epistemic membranes, seem to increase the opacity of many social phenomena. They are also changing the ways individuals are (automatically) identified, tracked, profiled or evaluated, often in real time, adding opacity (invisibility) to traditional systems of identification, evaluation and, thus, of "government". Automated, algorithmic systems are increasingly reading and editing behaviours, screening emotions, and calculating and measuring bodies, in order to profile users and to select the most appropriate information to display or decisions to propose. However, contrary to more classical social mechanisms of socialization and control, these systems are invisible and unintelligible as far as their actors and their normative frames are concerned. What is certain is that these processes challenge the notion of 'alterity', since they function on a principle of similarity-drawing profiles on what is common between individuals and similar others. In so doing, they raise the question of the possibility of an 'agora' as a space of difference and multiple "others".

Control of attention is overtly fought over in the arena of consumption. For companies to succeed, it is vital to master and anticipate the intentions of consumers. Understanding and predicting intentions displaces the technological objective from the current world, which needs to be organized and structured, to the future one, which needs to be discovered and possibly fabricated and controlled. The traces that consumers leave behind, and that are constantly combined with the traces of similar individuals, allow this reconfiguration of the future. They not only help to generate profiles of consumers but also, more significantly, orient consumers' access to and perception of information and thus the range of decisions they can make.

These new techniques to attract and channel our attention aim at shaping our intentions in a sort of prospective or virtual loop. This has two consequences: the first is reflected on time and the second on social relations. The temporality of consumption is different from that of production. In most organizations, the digitization of operations and processes has been seen as a source of rigidity and even fossilization of practices, freezing all actors in a digital cage. In the marketing world there is a different logic: the objective is to create in real time and constantly renew the profiles of consumers. These information systems are designed not to support the slow pace of the production process but to reflect the fleeting time of consumers' attention, which must be constantly renewed and stimulated.

The identities and social relations, which emerge from these profiles, are volatile and piecemeal; they create categories, which individualize and separate more than they link and generate solidarities. The epistemological impossibility of determining what lies behind the groupings of individuals prevents any form of collective belonging, because the social categories and classes are essentially statistical and fluctuating. Furthermore, none of these categories is stable; on the contrary, they are permanently fluctuating. It corresponds to what T. H. Eriksen (2001) beautifully called "l'hégémonie des fragments", the "hegemony of fragments".

Alongside their opaqueness, computational systems by definition reduce and standardize actions. Binary systems strive to increase similarities rather than differences, fragmenting experiences into common chunks and processes. This is true both "behind the scenes", in the logic of coding, and in the user interface, as attempts 
to thinly disguise the underlying entities with graphic interfaces cannot fully transform the common operations to be performed. The manipulation of symbolic elements on user interfaces that often carry the same logic across a great variety of tasks (manipulating a client record in a call centre is analogous to manipulating the configuration of temperature level in the control of an industrial process, which is not dissimilar to filling in a medical form) means that, from the cognitive perspective, users are operating at an extremely high level of abstraction and generality. This type of fragmentation of information, combined with the processes required by the computational models available, often decontextualizes single elements of information and contributes to users' sense of detachment. Finally, the fact that many activities are carried out as highly separated units and in social isolation also increases the sense of dis-embodiment.

To some extent, what we observe is the progressive dominance of a specific regime, which Boltanski and Thevenot (1991) would qualify as an industrial regime, based on predictions, risk management, evidence-based practices and 'procéduralisme'. The virtual and the real are questioned since what we observe in this evolution is part of what Kallinikos (2011) calls the long journey of human distancing from immediate, social, living context through its abstraction into formal systems and categories or the data-ification of life. Furthermore, most of these systems are increasingly considering the body and its biometric attributes as the only objective or authentic source of 'personal truth', based on the central hypothesis that "the body does not lie" (F. K. AAS 2006). The flip side of this assumption is a clear lack of confidence in people, their subjectivity and their agency.

Similarly, Merzeau (2009) observes that severing digital traces from their owners transforms them into entities available for administrative or commercial exploitation. Unbound from the person they belong to and identify, these traces are open to endless "remanufacturing as new strategies and requirements emerge." (p. 24). This same phenomenon of distancing and objectification is what H. Nissenbaum (2010) addresses when she talks about "the loss of contextual integrity" to describe the risks associated with ignoring identity when following Web traces.

In summary, we are seeing computational systems that develop techniques to bypass individual intentions in favour of bodily states and statistical averages, and a concurrent transformation of all experiences into fragmented elements of data. The combination of these two trends amplifies the difficulty of individuals to attribute meaningful categories to the information they are attending to and increases their dependence on external mediators to filter and structure the content they are exposed to.

\section{Interaction and Agency}

The fragmentation of activities that we describe above, and that Bolter says encourages users to "proceduralize their behaviour" (2012, p. 45), influences the tasks and actions of agents. More significantly, it blurs the limits between the agent's actions 
and the system's actions, in such a way that it becomes impossible for agents to distinguish between their intentions and the system's. In their interplay with the digital environments, therefore, systems' requests for attention are more than a simple appeal for the users' consciousness; they constitute an urgent request for participating in the action. However, this has been the case since the introduction of partially automated systems. What is new, and may have an even more distinctive effect on the definition of self, is the fragmentation of information and activities among networks of people through the digital systems. The collaborative online activities that now characterise the majority of "knowledge work" and that are being described in terms of swarms, collective intelligence, critical mass, etc. are perhaps the strongest manifestation of the shifting boundaries of the self. When we put together a network of agents who are individually fragmented by their interaction with their tools, and who organise their mutual activities around those fragments, is there an expansion or dilution of agency? Is the constant reciprocal appeal to contribute with small bits of information, tasks, exchange, just a more recent form of labour subdivision, or does it fundamentally alter the self's relation to others? Are we observing a growing instrumentation of relations that transforms others into data or, on the contrary - as many visionaries of the Internet (Rheingold 2002; Shirky 2008; Weinberger 2008) have asserted - the emergence of new forms of collective intelligence? The MIT Centre for Collective Intelligence has the following research question, which summaries the issue very well: "How can people and computers be connected so thatcollectively - they act more intelligently than any individual, group, or computer has ever done before?".

If this is the case, relinquishing attention to the collective flow is not a problem. Defending individual attention, as many popular commentators such as Nicholas Carr (2011) decry, is counterproductive, because attention must be renegotiated constantly for the collective intelligence to work. Phenomenologically, many people are already experiencing a sense of boundary redefinition between self and other when they are online (Gergen 2000). The experiences described by gamers, programmers and recently simply people who are heavily engaged in email exchanges, all suggest a sense of flow and participation that is described by some as a loss of agency, and by others as an exhilarating extension of means.

In order to understand how all of this is happening, we have to refer to our exceptional, species specific (as Tommasello 2008 has shown), capacity to join into other people's attention. The ability to envisage that other people have a state of mind different from one's own; the capacity to read other people's intentions; and, finally, the inclination to join into other people's attentional states, are skills that underlie human language, culture and co-construction. Joint attention is seen by developmental psychologists as a prerequisite for language acquisition, and is potentially what explains why humans are the only species that has developed language and advanced forms of collaboration. It is also potentially what is making the hyperconnection proper to the digital world such a double-edged sword. We are extraordinarily capable of collaborating with minimal information on very poor communication channels (think Twitter or SMS), because our powers of empathy are so developed and our capacity to infer and project meanings and intentions are 
supported by pragmatic processes of relevance (Sperber and Wilson 1995), which, again, rely on the sharing of attentional spaces. It is precisely this capacity for joint attention that causes us to feel lost in the inordinate flow of requests, messages, instructions and information so well described by Gergen (2000).

Our capacity to join into others' attentional spaces, read intentions from minimal traces, attribute meaning and co-ordinate around presumed shared mental states, means that we are able to collaborate on the reduced fragments of data because we can fill in the gaps. Clearly, when the experience is impoverished or the intentions of the other are too opaque and it is difficult to assume that the system is actually functioning with a principle of relevance, the communicational process becomes extremely costly. This cost may be part of the subjective feeling of loss and fatigue. In this case, the issue of attentional strain is not one of overload or excess, but of impoverishment, unintelligibility and incompleteness.

\section{Control and Self-Presentation}

It is not our intention to oppose a dystopic view of the digital revolution to an idealized era of authenticity and enhanced personal agency, characterized by the richness of face-to-face interaction and individuals' autonomous management of focus and attention. The social nature of attention, and its role in culture, language and collaboration, means that the control of attention is a cornerstone of social relations. The computational model of information organization is simply the most recent step in a long history of institutional management of this resource.

In many institutions, the mastery of attention has long been one of the axes of social dynamics, used to extract value, dominate, create allegiance, stratify and empower. It is this relational nature of attention management that Broadbent (2011) has called "attention to", attempting to shift the discourse from a purely cognitive one to a social one, where attention is a process that creates value. Teaching children to control their attention has been a significant objective of the educational system for as long as public education has been in operation. In the workplace, the equation between productivity and attention is deeply engrained in managerial models. This hypothesis is confirmed by T. Davenport and J. Beck (2001) when they claim that the effective allocation of employees' attention is a key factor in business competitiveness. If we look at this issue in a somewhat Marxist, Foucaldian and partisan reading, it can be seen as a step in the long path of the history of capitalism, as the contemporary page of the disciplinary conditions of life. The first page concerned the body and the shaping of a working force; the second page focused on knowledge and the development of the scientific organization of work. And now we are on the third page, which has attention as its object. Channelling, monitoring and controlling attention is engrained in work processes, rules, artefacts and now digital tools ${ }^{1}$.

\footnotetext{
${ }^{1}$ The political and economic challenges around attention management are made manifest by the way different organizations react and regulate access to personal communication channels, such
} 
The design of effective user interfaces, under the auspices of ergonomic and usability principles, ensures the elimination of potentially alternative perspectives or views, and focuses actions and reading on the prescribed elements of information, leaving very little to autonomous activity.

The ways in which different organizations regulate access to personal communication channels, such as mobile phones or Facebook, usually reveals deeper institutional ideologies. In broad terms, we find that greater freedom of access tends to be bestowed on those members of an organization who are expected to be "entrepreneurs of the self". In fact, providing or withholding unlimited access to potentially distracting sources dovetails perfectly with the larger movement of making each individual an "entrepreneur of the self".

In the eighties and nineties, N. Aubert and V. de Gaulejac (2007) argued, that the "ethics of excellence" in people management created the moral foundation of a system striving to control the totality of a person. In convincing employees that, by working for the firm, they were working for themselves, a complete blurring was made of professional and personal ambitions, and companies emerged as institutions capable of mediating individual destinies, supporting self-development, objects of true love, and in the end the only instrument able to fulfill the need for immortality of the self.

This work ethic creates particular interactions between people, interactions marked by the constant necessity to become visible. This quest for visibility takes the form of a new social game in which everyone is striving to capture the attention of others. In a sort of Goffmanian 'parade', self-branding and "newsing" oneself are ways to occupy the mental space of others and to stay on top of the competition. For businesses, being always present on personal communication channels, on webplatforms, etc., is a way to colonize the minds of their managers and to reduce their capacity to imagine another world.

\section{Intimacy as a Defence}

The new patterns of interaction that are emerging in highly digitized environments include the blurring of the boundaries between self and system and between self and others, and seem to engender a new typology of pathologies of which the most

as mobile phones or Facebook, and uncover some significant social dynamics surrounding the control of this process. Rules and procedures are devised in organizations to exclude personal devices or personal digital activities while on the job (by blocking external websites, or internet access, or mobile phones). The digital surveillance of all online activities, through dedicated surveillance software, can give rise to sanctions or the elimination of potentially distracting digital spaces. On the opposite end, obtaining "digital trust" or "digital independence" is a sign of status, of trustworthiness, of social promotion and acceptance. Having access to the whole range of the web, to personal communication devices and services, or in general being granted the "freedom" of self-determining when and where to put one's attention in the realisation of one's activities, is the ultimate sign of social recognition and of higher social status. 
common is what is being described as 'burn out'. This is characterized by the paradoxical feelings of being permanently exhausted, overloaded, under pressure, and yet not being able to achieve what is expected and losing productivity. While not new as a set of symptoms, the expectations of permanent availability and self promotion associated with the professional model of the "entrepreneur of the self" has heightened the sense of disorientation. Controlling the attention of others, and dealing with the constant solicitation of others, is accompanied by a dramatic sense of loss of self-direction, intentionality and planning.

The French expression of for intérieur can help us understand the human issues at stake here. In Latin, 'for' means jurisdiction. The common understanding (not the ecclesiastic one) of the for interieur is the jurisdiction that each person applies to her/himself; it corresponds to what in social sciences is called a sense of agency. Managers and employees in organizations that are heavily reliant on digital environments, such as banks, public administrations, large corporations, describe a sort of permanent blurring between their interior life and their life online. They describe the difficulty of making their for intérieur exist vividly in their daily lives. They talk of burning from the inside. This sense of disorientation is not unique to workplaces, and seems to be emerging in the home. The feeling of losing a sense of control when engaged with digital devices is described equally by gamers, online shoppers, video consumers or social media participants. Invariably, users talk of their devices as "time sucks", as environments in which they lose their intentions and agency.

Another facet of the same problem is what R. Sennett (1977) describes as the current tyranny of intimacy - that is, the central position of intimate relations in the perception of self-realization. In contrast to traditional patterns of social interactions, organized through distinct roles where individuals were more easily categorized as workers, lovers, parents, citizens, we now observe a greater fluidity and confusion of boundaries. Nowadays, observes Sennett, the king is naked. Social distances, masks and shelters have disappeared. Individuals have no sanctuaries to retreat to and hide from the scrutiny of others, but feel always visible and transparent... raising obvious questions for the plurality of social identities. To some extent, this explains the increasing position of the home and of the inner circle of the family as a protective cocoon and the growing success of activities such as cooking and gardening, which restore the sense of duration, agency and privacy.

On the digital side, we also have evidence of a retreat into the private, intimate and controllable. There is ample evidence showing that all new digital communication channels, from texting to Skype, from Facebook to instant messaging, are being used to strengthen people's closest and most intimate relations (Baym 2010; Broadbent 2011; Madianou and Miller 2012). Contrary to common public discourse, people have not hugely extended their social network nor do they spend much time communicating with unknown digital acquaintances. Close scrutiny of what people actually do, with all the channels they have at their disposal, shows an intensification of exchanges with a few close ties, often less than five, leading to the strengthening of these relationships. A recent survey of 3,000 teenagers in Belgium (Gallez and Lobet-Maris 2011) confirmed the results of similar studies in the US (Ito 2010), showing that most of the participants had an 'between us' connectivity 
based on intense chatting and messaging with the small circle of the friends they have in 'real life'. The blurring of their off- and online lives leads them to consider the virtual world as just another social space where they can entertain continuous contact with an intimate group of friends and relations. This constant and ubiquitous link between individuals and their loved ones is emotionally intense, and the feeling of always being within reach can provide a profound sense of safety and comfort. However, concentrating so intensely on a small set of relationships - especially when they also function as information filters, as is increasingly happening on social networking services - dramatically reduces the exposure to "others".

Social media are playing a significant role in filtering information: news and content are chosen and filtered by friends. The much hailed principle of sharing interesting and relevant content with friends, a principle trumpeted as a way to actively participate in the making of news, is also, by a simple principle of homophily, reducing our exposure to diversity. The homogeneity of the social groups that compose the majority of people's close personal connections, ensures that the information circulated within the network is highly consensual and supportive of the values of the group.

In conclusion, we observe this retreat into the intimate as an attempt to regain a sense of mastery of attention and agency. This attempt is marked by the pursuit of a "protective cocoon", which corresponds to an extreme form of filtering of social and relational information. When digital environments become too opaque, and experiences too abstract and remote, the solution is to fall back onto what is extremely familiar.

\section{Grey Ecology as an Ecology of Agency and Alterity}

The term "grey ecology" was introduced by P. Virilio in 2010, as a way of reflecting on the effects that the by-products of the digital revolution have on the human mind. In his work on the dromosphere (the space of technological acceleration), Virilio argued that just as accidents are intrinsic to technological innovation, pollution is the side effect of progress and, to some extent, its 'normal' but unacceptable companion. While many of the risks of the digital era are well known - the encroachment on privacy, extreme state surveillance, viral attacks, network meltdowns, data theft, etc. - and there is an active engagement on the part of experts, institutions and the public to find technical and political solutions to limit their impact, there is far less concern about digital pollution. In fact, pollution in the computational era evokes images of e-waste, old desktop computers strewn in open-air dumps, overheated data farms and silicon mines. But ecology does not simply refer to overconsumption, toxicity and waste; it also refers to equilibrium and diversity. What we want to suggest here is that one of the social prices being paid for the exponential increase of information is a reduction in the diversity of perspectives. The pervasive and obscure tracking of our digital life, and its real-time transformation into a myriad of fragmented and contextualized profiles, creates a sort of epistemic membrane, 
which makes social identity and social belonging less understandable and more complex.

In a very similar vein, D. Quessada (2007) argues that the hegemony of dynamic differences makes the figure of the Other slowly disappear: "It seems that we now live in a proliferation of differences. It is not at all the same as the otherness (l'altérité). The all-round contemporary exaltation of difference is perhaps the clearest sign of the disappearance of otherness. When humans prevent themselves to be crossed by a founding division, $[\ldots]$ the setting necessary for the existence of the Other disappears and all figures vanish one after the other-whether in the form theological, political or ontological." (p. 5) The brutality or the violence of this process could be related to the progressive disappearance of the social habitus (Bourdieu 1979), due to the extreme individualization and opacity of profiling and attention channeling mechanisms. The habitus was both a guarantee of a socially shared (class) episteme of the world and a collective protection against the world's complexity and uncertainty. To say this in Goffmanian terms: we are losing the rituals and the codes that, when interacting with others who are different from us, help us to preserve our face while preserving the face of the other-a skill and process which is at the very root of social ties.

Without going as far as A. Touraine (1993), for whom the rationalization of life has progressively destroyed the traditional correspondence between social organization and personal life, leading to a massive de-socialization, we do believe that there is a tension around agency in the digital environments.

According to Virilio (1995), the transformation in the sense of agency leads to a dramatic loss of orientation, a significant disturbance in one's relationship with oneself, the others and the world, which in turn has tremendous consequences for the sense of alterity and for democracy: "The specific negative aspect of information superhighways is precisely the loss of orientation regarding alterity (the other), a disturbance in the relationship with the other and with the world. It is obvious that this loss of orientation, this non-situation, is going to usher a deep crisis which will affect society and hence, democracy" (p. 1).

In the previous industrial age of "solid modernity" (Bauman 2001), exploitation, poverty and class conflicts both triggered and sustained the establishment of collective movements, making possible an industrial democracy. In the age of digital postmodernity, any collective movement (ex pluribus unum) is difficult to operate due to the opacity of the 'digital assemblage' and to the extreme individualization of our digital lives. And this, as already pointed out, leads to the loss of a clear figure of otherness. For A. Gorz (1993), "Classical class analysis cannot provide an answer to the question of which social forces would be capable of achieving these transformations. There is no central front where decisive battles can be won through class confrontation. In other words, the front is everywhere, because the power of capital is exercised in a diffuse fashion in every area of life" (p. 62) We suggest that Virilio's concept of grey ecology can help us to reflect on how to protect our attention, and how to restore our sense of self, agency and social orientation. Grey ecology can be considered as an invitation to politicize our concerns about our human and mental resources, just as green ecology is doing with the natural resources. A 
Grey ecology could open the door to new forms of solidarity by establishing a new front of collective engagement and general interest. To understand what this front would be defending, we could draw a parallel with what happened to the 'artisans' at the end of the nineteenth century. Over a hundred years ago the skills and gestures of craftsmen and women were incorporated into a scientific organizational regime and then automated. More recently it is our personal data, history and digital traces that are being captured. So now, as in the past, we are witnessing the process of expropriation of human prerogatives. The defence of attention can thus be situated in a long tradition of humanistic movements and conceptualized as a political and collective concern, and a new front for solidarity and resistance.

Two main observations legitimate this reference to 'ecology'. First, as A. Gorz states (1993), ecology represents the tension between the "life-world" and the "quantification and monetary valuation of life". It opposes the substitution of individuals' autonomy and capacity for self-determination by mercantile, dependent, client relations. And second, ecology as a social and cultural movement is possibly the most relevant means of 'resistance' to digital fragmentation and its opaqueness. As S. Rodota (1999) asserts, ecology is a promising cultural and political path because it concerns people's attitudes and lifestyles, and so allows a shared reflexivity on digital technologies and the pollution they engender, thus avoiding sterile pro and con debates. Ecology is also a means of spreading forms of cultural vigilance which can be promoted in schools and the media. And finally, it can direct political and industrial authorities towards actions and research which promote "clean technologies" - that is, technologies which are sustainable in respect to our attention and our capacity of self-determination and accountable regarding the processes they perform to fabricate identities and differences. To some extent, a step in this direction has already been taken by the European Regulator when it decided to introduce the concept of 'Data Minimization' into the project of personal data regulation in order to protect European citizens from the uncontrolled processing of their personal data.

Hannah Arendt warned us long ago that "miracles and catastrophies are two sides of the same coin". In line with her concept of natality, could the grey ecology be the possibility of a new beginning?

Open Access This chapter is distributed under the terms of the Creative Commons Attribution Noncommercial License, which permits any noncommercial use, distribution, and reproduction in any medium, provided the original author(s) and source are credited.

\section{References}

AAS, F. K. 2006. 'The body does not lie': Identity, risk and trust in technoculture. Crime Media Culture 2 (2): 143-158.

Aubert, N., and V. De Gaujelac. 2007. Le coût de l'excellence. Le seuil: Paris.

Bauman, Z. 2001. The individualized society. Cambridge: Polity. ISBN 0-7456-2506-1.

Bauman, Z. 2005. Franchir les frontières -ou avoir de nombreux chez-soi? Tumultes 24:79-89. 
Bauman, Z. 2007. Le présent liquide. Peurs sociales et obsessions sécuritaires. Le Seuil: Paris.

Baym, N. 2010. Personal connections in the digital age. Cambridge Polity Press: Cambridge.

Beck, U. 2001. Risikogesellschaft. Francfort: Suhrkamp Verlag. French edition: 2001. La Société du risque. Sur la voie d'une autre modernité (trans: L. Bernardi). Éditions Aubier: Paris.

Boltanski, L., and L. Thévenot. 1991. De la justification. Les économies de la grandeur. Gallimard: Paris.

Bolter, J D. 2012. Procedure and performance in an era of digital media. In Producing theory in a digital world: The intersection of audiences and production in contemporary theory, ed. Rebecca Ann Lind, 33-50. Peter Lang: New York.

Bourdieu, P. 1979. La distinction. Paris: Les éditions de Minuit.

Boyd, D. 2007. Why youth (heart) social network sites: The role of networked publics in teenage social life. In MacArthur foundation series on digital learning-youth, identity, and digital media volume, ed. David Buckingham, 119-142. Cambridge: MIT Press.

Broadbent, S. 2011. L'intimité au Travail. Paris: FYP Editions.

Burk, D. 2011. Comments on P. Virilio. http://www.ctheory.net/articles.aspx?id=681. Accessed 15 March 2014.

Carr, N. 2011. The shallows: What the internet is doing to our brains. New York: Norton and Company.

Castel, R. 1995. Les Métamorphoses de la question sociale, une chronique du salariat. Paris: Fayard.

Chambers, D. 2013. Social media and personal relationships: online intimacies and networked friendship. Hampshire: Palgrave Macmillan.

Davenport, T. H., and J. C. Beck. 2001. The attention economy. Ubiquity. http://doi.acm. org/10.1145/376625.376626. Accessed 15 March 2014.

Dubet, F., and D. Martuccelli. 1988. Dans quelle société vivons-nous? Paris: Éditions du Seuil.

Eriksen, T. H. (2001) Tyranny of the moment: Fast and slow time in the information age. London: Pluto Press.

Gallez, S., and Lobet-Maris, C. 2011. Les jeunes sur Internet. Se construire un autre chez-soi. Communication 28/2. http://communication.revues.org/index1836.html. Accessed 15 March 2014.

Gergen, K. 2000. The saturated self. New York: Basic Books.

Goldhaber, M. H. 1997. The attention economy on the net. First monday. doi:http://dx.doi. org/10.5210\%2Ffm.v2i4.519. Accessed 15 March 2014.

Gorz, A. 1993. Political ecology: Expertocracy versus self-limitation. New Left Review 202:55-67.

Harvey, D. 2008. Géographie de la domination. Paris: Les prairies ordinaires.

Hutchins, E. 1995. Cognition in the wild. MIT Press. ISBN 0-262-58146-9.

Kallinikos, J. 2011. Governing through technology information artefacts and social practice. Basingstoke: Palgrave Macmillan.

Kessous, E., K. Mellet, and M. Zouinar. 2010. L'économie de l'attention. Sociologie du travail 52:359-373.

Lanier, J. 2011. You are not a gadget. New York: Vintage Books.

Madianou, M., and Miller, D. 2012. Migration and new media: Transnational families and polymedia. London: Routledge.

Marulanda-Carter, L., and T. W. Jackson. 2012. Effects of e-mail addiction and interruptions on employees. Journal of Systems and Information Technology 14 (1): 82-94.

Misra, S., and D. Stokols. 2012. Psychological and health outcomes of perceived information overload. Environment and Behavior 44 (6): 737-759.

Nissenbaum, H. 2010. Privacy in context: Technology, Policy, and the integrity of social life, Palo Alto, CA: Stanford University Press.

Quessada, D. 2007. La mort de l'Autre. Biblio Obs: 4-12. http://bibliobs.nouvelobs.com/essais/20071204.BIB0428/la-mort-de-1-039-autre.html. Accessed 15 March 2014.

Rheingold, H. 2002. Smartmobs: The next social revolution. New York: Basic Books.

Rodota, S. 1999. La démocratie électronique. Paris: Editions Apogée.

Ros, A., and S. De La Fuenta Vilars. 2011. Through the webcam: Bolivian immigrant women in Barcelona communicating with their families back home. Proceedings of Digital diasporas Conference, Cambridge. 
Sennett, R. 1977. Les tyrannies de l'intimité. Paris: Le Seuil.

Shirky, C. 2008. Here come everybody: The power: The power of organizing without organizations. Westminstre: Penguin Press.

Simon, H. A. 1971. Designing organizations for an information-rich world, in Martin Greenberger, Computers, Communication, and the Public Interest, Baltimore, MD: The Johns Hopkins Press. ISBN 0-8018-1135-X.

Sperber, D., and D. Wilson. 1995. Relevance: Communication and cognition. 2nd ed. Oxford: Blackwell Publishers.

Tommasello, M. 2008. Origins of human communication. Cambridge: MIT Press.

Touraine, A. 1993. The crisis of the progress. European Review 1 (2): 117-123.

Turkle, S. 2011. Alone together why we expect more from technology and less from each other. New York: Basic Books.

Virilio, P. 1995. Speed and information: Cyberworld alarm. www.ctheory.net. Accessed 27 Aug 1995.

Virilio, P. 1999. La vitesse de l'information. http://www.ctheory.net/articles.aspx?id=72. Accessed 15 March 2014, Août.

Virilio, P. 2010. Grey ecology. Trans: D. Burk. New York: Atropos Press.

Weinberger, D. 2008. Everything is miscellaneous: The power of new digital disorder. New York: Henry Holt and Company Inc.

Zeldes, N., A. Sward, and S. Louchheim. 2007. Infomania why we can't afford to ignore it any longer. First monday. doi:http://dx.doi.org/10.5210\%2Ffm.v12i8.1973. 